\title{
Oral Health-related Knowledge and Assessment of Oral Health Status of Diabetic Patients Attending Dental Clinic at College of Dentistry, Hail, Kingdom of Saudi Arabia
}

Rashid I Mian ${ }^{1}$, Fawzeyah FH Rashidi ${ }^{2}$, Tahani M Alshammary ${ }^{3}$, Saad Al Zubaidi ${ }^{4}$, Freah Al Shammary ${ }^{5}$, Ammar A Siddiqui $^{6}$, Junaid Amin 7 , Rabia S Khan ${ }^{8}$

\begin{abstract}
Aim: This study was aimed to evaluate the oral health status and knowledge of diabetic and nondiabetic patients attending dental clinic at College of Dentistry, Hail, the Kingdom of Saudi Arabia.

Materials and methods: It was an observational cross-sectional study. Using nonprobability convenient sampling technique, data were collected from 202 respondents. A total of 202 diabetic and nondiabetic patients were screened for the study. Data were collected by interview using the structured, self-administered questionnaire, and assessment of oral health status was done by clinical examination. The collected data were analyzed using IBM SPSS software. The data were displayed as numbers and percentages and association among the variable of interests was measured using Pearson Chi-square.

Results: Of the 202 patients, 102 (50.6\%) were males and 100 (49.4\%) were females. Majority of the patients, 71 (35.2\%) were in the age-group of 30-40 years. In all, 128 (63.4\%) participants knew the effect of diabetes mellitus (DM) on oral health, 167 (82.7\%) knew that diabetic patients needed special healthcare, $152(75.25 \%)$ had never spoken to their doctors about oral health, and $164(81.19 \%)$ had never spoken to their dentists regarding diabetes.

Conclusion: The complications associated with oral health are more common in diabetic patients when compared to the nondiabetic patients. This is the case in both male and female patients visiting the College of Dentistry in the Hail region.

Clinical significance: Diabetes mellitus is associated with increased susceptibility to oral infections especially periodontal disease. Role of a general dentist in diagnosis and raising patient awareness toward DM and its effects on oral health need to be emphasized.

Keywords: Diabetes mellitus, Hail, Oral health, Periodontal diseases.

The Journal of Contemporary Dental Practice (2020): 10.5005/jp-journals-10024-2729
\end{abstract}

\section{INTRODUCTION}

Type 2 diabetes mellitus (T2DM) may lead to several oral complications such as xerostomia, infections, poor healing, candidiasis, caries' severity, several periodontal diseases, and burning mouth disorders. ${ }^{1}$ According to the recommendations of International Diabetes Federation, healthcare professionals at primary health centers should assess diabetic individuals (i) for routine of recommended oral self-care habits and (ii) for early signs of oral health problems and (iii) also provide recommendations to improve self-care and refer to a dentist. Several epidemiological studies have been carried out to understand the association between systemic health and periodontal diseases. ${ }^{2}$ Periodontal disease is considered as "sixth complication" in addition to the already established five complications of DM, e.g., retinopathy, neuropathy, nephropathy, altered wound healing, and macrovascular disease. ${ }^{3}$ Gingivitis and its associated conditions are more commonly seen in poorly controlled insulin-dependent diabetes when compared to the controlled insulin-dependent diabetes. The increase in periodontal diseases occurs due to a change in host response, subgingival microflora, vascularity, and collagen metabolism. ${ }^{4}$

The periapical inflammatory disease shows some resemblance to chronic periodontal diseases. Chronic infection within the oral cavity is caused by gram-negative aerobic bacteria and enhanced cytokines levels. ${ }^{5}$ Diabetic patients are more inclined to different endodontic and periodontal problems. ${ }^{6}$ The periodontal diseases
1,4 Department of Restorative Dentistry, University of Hail, Hail, Kingdom of Saudi Arabia

2,3 Primary Health Care, Ministry of Health, Hail, Kingdom of Saudi Arabia

${ }^{5,6}$ Department of Preventive Dentistry, University of Hail, Hail, Kingdom of Saudi Arabia

${ }^{7}$ Department of Physiotherapy, University of Hail, Hail, Kingdom of Saudi Arabia

${ }^{8}$ Department of Engineering, Lancaster University, Lancaster, UK

Corresponding Author: Ammar A Siddiqui, Department of Preventive Dentistry, University of Hail, Hail, Kingdom of Saudi Arabia, Phone: +966 553226295, e-mail: a.siddiqui@uoh.edu.sa

How to cite this article: Mian RI, Rashidi FFH, Alshammary TM, et al. Oral Health-related Knowledge and Assessment of Oral Health Status of Diabetic Patients Attending Dental Clinic at College of Dentistry, Hail, Kingdom of Saudi Arabia. J Contemp Dent Pract 2020;21(1):78-82. Source of support: Nil

Conflict of interest: None

are found to a greater extent in patients with diabetes for a long duration when compared to those with diabetes for short duration. However, the same frequency was seen in diabetic and nondiabetic patients concerning caries. The apical periodontitis with infection can be controlled by root canal treatment and has a high success rate. ${ }^{7}$ However, the failure rate increases in the case of diabetic 
patients compared to nondiabetic patients. Oral diseases are acknowledged as a major issue affecting the global public health. Gingivitis and periodontitis are common in diabetic patients compared to those without diabetes. A previous study detected chronic periodontitis, tooth mobility, and furcation involvement were most common among DM patients compared to nondiabetic patients. ${ }^{8}$

Research in the past decades has well established the fact that periodontal disease and tooth loss are associated with systemic metabolic disorders such as DM. It is now acknowledged that DM adversely affects periodontal tissues supporting the tooth. In 2011, an international conference on diabetes and oral disease by the New York Academy of Sciences focused on DM-periodontal problems and recommended a multidisciplinary approach of a medical and oral health professional with DM patients to achieve the desired clinical outcomes. Thus, the DM-periodontal disease connection is highly considered in clinical practice. ${ }^{9}$ With the advent of terminologies such as periodontal medicine, the role of a dentist is all the more imminent and cannot be undermined in a symbiotic relationship with physicians in the management of patients affected by DM. For some patients, dental visits may be the only exposure to the healthcare system, which highlights the importance of including diabetes risk assessment for patient well-being.

In 2014, the World Health Organization (WHO) reported that Saudi Arabia ranked second in the Gulf and seventh in the worldwide, with 7 million people diagnosed with diabetes. In 2014, community-based national epidemiological health survey reported $32.8 \%$ prevalence of DM in Saudi population, with $26.2 \%$ being males and $21.5 \%$ females. ${ }^{10}$ Likewise, in 2014, an epidemiological survey of Hail city reported an overall high prevalence $(31.1 \%)$ of DM; and in men it is $32.6 \%$ and women $29.6 \% .^{11}$

The aim of the present study was to report oral health-related knowledge of diabetic and nondiabetic patients attending College of Dentistry clinics. To our best knowledge, this was the first study of its kind in Hail region, Saudi Arabia. This study will give an overview of participants' oral health knowledge in contrast to DM and will lead as a baseline for future research in this regard.

\section{Materials and Methods}

It was an observational study, having a cross-sectional design, approved by the Research Ethical Committee of University of Hail, with an approval number $\mathrm{H}-2018-070$. The present study was conducted in Hail city located in North-West of Saudi Arabia with a population of approximately 412,758 . The sample size of the study was 202 patients, male $(n=102)$ and female $(n=100)$, with age ranging between 30 years and 60 years, attending dental clinics at College of Dentistry. The data were collected using nonprobability, convenient sampling technique. Verbal and written informed consent was taken from all participants before collecting data. Participants were interviewed by a single trained research assistant using a self-administered validated standardized structured questionnaire including sociodemographics and oral health-related knowledge. Reliability of the study tool was pretested pre and postinterview using the above-mentioned questionnaire. Internal consistency was measured using Cronbach's a test and was found to be in an acceptable category if it is 0.77 . Data were collected from March 2018 to December 2018. Individuals with disabilities or having any systematic disease except T2DM were included as a sample of the present study. Patients with T1DM, those below 30 years of age, and those above 60 years were excluded from the study. Data were also collected by doing clinical examination comprising the plaque index and coronal caries using the decayed, missing, and filled teeth (DMFT) index. For each participant, root surface caries was recorded (yes/no) and expressed as the percentage of teeth with root caries. Tools used for the examination were (N22) color-coded probe 2-4-6-8-10-12 mm markings, mouth mirror, explorer, gauze cotton roll, and plaque disclosing tablets. Clinical examination was done by a licensed dentist.

The collected data were entered, coded, and analyzed using SPSS version 21. Data were displayed as descriptive statistics as numbers and percentages. Pearson Chi-square test was used for reporting inferential statistics. $p$ values of less than 0.05 were considered significant.

\section{Results}

Total eligible participants were 237, but 202 agreed to participate in this study, giving a response rate of $85.23 \%$. In all, $22(10.9 \%)$ DM male and 80 (39.7\%) non-DM male; 50 (24.7\%) DM female and 50 (24.7\%) non-DM female patients) were examined to determine their oral health status.

The study sample included 102 (50.6\%) male and 100 (49.4\%) female patients. Among these, a total of 22 (10.9\%) male and 50 (24.7\%) female were diabetic patients. In this study, the majority of patients, $71(35.2 \%)$ were in the third to the fourth decade, followed by $66(32.6 \%)$ in the 5 th-6th decade of age-group. Most of the diabetic patients were in the 5 th-6th decade, i.e., 12 (54.5\%) males and 34 (68\%) females. Most of the respondents, 74 (36.6\%) and 60 (29.7\%) of the study population, had university and higher secondary level education, respectively, and only 24 (11.9\%) were without any education. The 20 (40\%) female patients with DM and 20 (40\%) non-DM female patients had a primary level of education. The 17 (77.3\%) male patients with DM and 27 (33.8\%) studied higher secondary education and 51 (63.7\%) male non-DM patients studied university level of education. Majority 104 (51.5\%) of the patients were earning an income in the range of 3,000 to 10,000 Saudi Riyals (SR) per month. The monthly income of 20 (40\%) female patients with DM was $<3,000$ SR, while $15(68.2 \%)$ male patients with DM and 26 (52\%) female patients with DM were earning between 3,000 SR and 10,000 SR (Table 1).

Majority of the respondents, i.e., 144 (71.3\%), reported that they visit dentists only upon feeling pain. In all, 18 (81.8\%) male patients with DM and 36 (72\%) female patients with DM visited their dentists only on feeling pain. In all, 128 (63.4\%) patients were aware of the oral issues associated with diabetes. Of those, 13 (59.1\%) male DM and 42 (84\%) female DM were aware of the effect of diabetes on oral health. Majority of the patients, $167(82.7 \%)$ were aware that diabetic patients needed special healthcare, of those $18(81.8 \%)$ were male patients with DM and 43 (86\%) female patients with DM (Table 2).

In response to any changes observed in oral health status, 35 (32.11\%) female patients with DM complained of dry mouth. A total of 97 (31.49\%) patients complained of decayed teeth, among which 10 (27.8\%) were male patients with DM and 20 (18.35\%) were female patients with DM.

A total of 69 (22.4\%) patients were reported complaining about the bleeding gums, with $26(23.85 \%)$ being female patients with DM. Only a few patients, i.e., 9 (2.92\%) complained of ulcers; among these, 2 (5.6\%) were male DM and 3 (2.75\%) female DM patients. In all, $15(68.18 \%)$ male patients with DM and 38 (76\%) female patients with DM were among the 152 (75.25\%) patients who had never talked to their doctors about their oral health. A noticeable number 
Table 1: Sociodemographic characteristics of the participants (stratified by gender and DM/non-DM patients)

\begin{tabular}{|c|c|c|c|c|c|c|c|}
\hline \multirow[b]{3}{*}{ Variables } & & \multicolumn{2}{|c|}{ Male } & \multicolumn{2}{|c|}{ Female } & \multirow[b]{2}{*}{ Total } & \multirow[b]{3}{*}{$p$ value } \\
\hline & & $D M$ & Non-DM & $D M$ & Non-DM & & \\
\hline & & $n(\%)$ & $n(\%)$ & $n(\%)$ & $n(\%)$ & $n(\%)$ & \\
\hline \multirow[t]{3}{*}{ Age } & $30-40$ years & $1(4.54)$ & $43(53.7)$ & $5(10)$ & $22(44)$ & $71(35.2)$ & 0.474 \\
\hline & $41-50$ years & $9(40.9)$ & $29(36.3)$ & $11(22)$ & $16(32)$ & $65(32.2)$ & \\
\hline & $51-60$ years & $12(54.5)$ & $8(10)$ & $34(68)$ & $12(24)$ & $66(32.6)$ & \\
\hline Gender & Male/female & $22(10.9)$ & $80(39.7)$ & $50(24.7)$ & $50(24.7)$ & $202(100)$ & 0.531 \\
\hline \multirow[t]{4}{*}{ Level of education } & Primary & $2(9.1)$ & $2(2.5)$ & $20(40)$ & $20(40)$ & $44(21.8)$ & 0.0008 \\
\hline & Higher secondary & $17(77.3)$ & $27(33.8)$ & $9(18)$ & $7(14)$ & $60(29.7)$ & 0.0017 \\
\hline & University & $3(13.6)$ & $51(63.7)$ & $6(12)$ & $14(28)$ & 74 (36.6) & 0.0010 \\
\hline & Without education & $0(0)$ & $0(0)$ & $15(30)$ & $9(18)$ & 24 (11.9) & 0.139 \\
\hline \multirow[t]{4}{*}{ Monthly income } & $<3,000$ & $4(18.2)$ & $7(8.8)$ & $20(40)$ & $18(36)$ & $49(24.2)$ & 0.0004 \\
\hline & $3,000-10,000$ & $15(68.2)$ & $39(48.8)$ & $26(52)$ & $24(48)$ & $104(51.5)$ & 0.0056 \\
\hline & $>10,000$ & $3(13.6)$ & $33(41.2)$ & $3(6)$ & $6(12)$ & $45(22.3)$ & 0.0059 \\
\hline & Without income & $0(0)$ & $1(1.2)$ & $1(2)$ & $2(4)$ & $4(2)$ & 0.428 \\
\hline
\end{tabular}

Table 2: Assessment of participants' knowledge (stratified by gender and DM/non-DM)

\begin{tabular}{|c|c|c|c|c|c|c|c|}
\hline \multirow[b]{3}{*}{ Variables } & & \multicolumn{2}{|c|}{ Male } & \multicolumn{2}{|c|}{ Female } & \multirow{3}{*}{$\begin{array}{l}\text { Total } \\
n(\%)\end{array}$} & \multirow[b]{3}{*}{$p$ value } \\
\hline & & \multirow{2}{*}{$\frac{D M}{n(\%)}$} & \multirow{2}{*}{$\begin{array}{l}\text { Non-DM } \\
n(\%)\end{array}$} & \multirow{2}{*}{$\frac{D M}{n(\%)}$} & \multirow{2}{*}{$\begin{array}{l}\text { Non-DM } \\
n(\%)\end{array}$} & & \\
\hline & & & & & & & \\
\hline \multirow[t]{4}{*}{ How often do you visit dentists? } & Once a year & $1(4.55)$ & $19(23.7)$ & $6(12)$ & $10(10.5)$ & $36(17.8)$ & 0.0201 \\
\hline & Twice a year & $3(13.64)$ & $0(0)$ & $2(4)$ & $50(52.6)$ & $10(5.0)$ & \\
\hline & Thrice a year & $0(0)$ & $0(0)$ & $6(12)$ & $6(6.3)$ & $12(5.9)$ & \\
\hline & Only on feeling pain & $18(81.8)$ & $61(76.3)$ & $36(72)$ & $29(30.6)$ & $144(71.3)$ & \\
\hline \multirow{2}{*}{$\begin{array}{l}\text { Do you know diabetes can } \\
\text { affect oral health? }\end{array}$} & Yes & $13(59.1)$ & $38(47.5)$ & $42(84)$ & $35(70)$ & $128(63.4)$ & 0.0029 \\
\hline & No & $9(40.9)$ & $42(52.5)$ & $8(16)$ & $15(30)$ & $74(36.6)$ & \\
\hline \multirow{2}{*}{$\begin{array}{l}\text { Do you know diabetic } \\
\text { patients need special } \\
\text { healthcare? }\end{array}$} & Yes & $18(81.8)$ & $66(82.5)$ & $43(86)$ & $40(80)$ & $167(82.7)$ & 0.065 \\
\hline & No & $4(18.2)$ & $14(17.5)$ & $7(14)$ & $10(20)$ & $35(17.3)$ & \\
\hline \multirow{6}{*}{$\begin{array}{l}\text { Have you noticed any of the } \\
\text { mentioned change in your } \\
\text { mouth lately? }\end{array}$} & Dry mouth & $6(16.6$ & $2(2.13)$ & $35(32.11$ & $10(14.49)$ & $53(17.21)$ & 0.019 \\
\hline & Decayed teeth & $10(27.8)$ & $42(44.68)$ & $20(18.35)$ & $25(36.23)$ & 97 (31.49) & \\
\hline & Missing teeth & $10(27.8)$ & $9(9.57)$ & $24(22.02)$ & $13(18.84)$ & $56(18.19)$ & \\
\hline & Bleeding gums & $7(19.4)$ & 17 (18.09) & $26(23.85)$ & $19(27.54)$ & $69(22.40)$ & \\
\hline & $\begin{array}{l}\text { Other changes (abscess, } \\
\text { ulcer, sensitivity) }\end{array}$ & $2(5.6)$ & $3(3.19)$ & $3(2.75)$ & $1(1.45)$ & $9(2.92)$ & \\
\hline & There is no change & $1(2.8)$ & $21(22.34)$ & $1(0.92)$ & $1(1.45)$ & $24(7.79)$ & \\
\hline \multirow{2}{*}{$\begin{array}{l}\text { Have you ever talked to your } \\
\text { doctor about diabetes and oral } \\
\text { health }\end{array}$} & Yes & $7(31.82)$ & $26(32.5)$ & $12(24)$ & $5(10)$ & $50(24.75)$ & 0.013 \\
\hline & No & $15(68.18)$ & $54(67.5)$ & $38(76)$ & $45(90)$ & $152(75.25)$ & \\
\hline \multirow{2}{*}{$\begin{array}{l}\text { Have you ever talked to your } \\
\text { dentist or a dental hygienist } \\
\text { about your diabetes? }\end{array}$} & Yes & $7(31.82)$ & $22(27.5)$ & $8(16)$ & $1(2)$ & $38(18.81)$ & 0.118 \\
\hline & No & $15(68.18)$ & $58(72.5)$ & $42(84)$ & $49(98)$ & $164(81.19)$ & \\
\hline
\end{tabular}

of $164(81.1 \%)$ patients had never reported to their dentists or the dental hygienists about their diabetes, among these 15 (68.18\%) were male patients with DM and 42 (84\%) were female patients with DM (Table 2).

Majority of the male and female patients with DM showed poor plaque index of around 59.09 and $60 \%$, respectively. Most of male and female non-DM patients showed fair plaque index of about 21.25 and $40.1 \%$, respectively. This indicated that patients with DM showed poor oral health and had poor plaque index, while the non-DM patients showed fair oral health with fair plaque index. The $p$ value for the poor plaque index was statistically significant " $p<0.05$ " using the Chi-square test. The $p$ value for income and education is 0.009 and 0.039 , respectively, which is less than 0.05 . This reflects that the poor plaque index is statistically significant, among those with both no income and no educational background. High income and higher education background influence the plaque index, as they were more aware of oral hygiene and also had proper maintenance of their teeth (Table 3).

Most of the male patients with DM, 7 (31.82\%) showed a caries index of $18-25$ and 8 (36.36\%) showed $25-32$ caries index (DMFT), whereas the male non-DM patients of about $45 \%$ showed $11-18$ caries index (DMFT). Majority of the female DM patients, i.e., 19 (38\%), and non-DM patients, i.e., 16 (32\%), showed a caries index (DMFT) of about 20-26 range. In 15 (30\%) DM female patients and 
Oral Health-related Knowledge and Assessment of Oral Health Status of Diabetic Patients

Table 3: Assessment of plaque index (stratified by gender and DM/non-DM)

\begin{tabular}{|c|c|c|c|c|c|c|c|}
\hline & & \multicolumn{2}{|c|}{ Male } & \multicolumn{2}{|c|}{ Female } & \multirow[b]{2}{*}{ Total } & \multirow[b]{3}{*}{$p$ value } \\
\hline & & $D M$ & Non-DM & $D M$ & Non-DM & & \\
\hline \multicolumn{2}{|l|}{ Variables } & $n(\%)$ & $n(\%)$ & $n(\%)$ & $n(\%)$ & $n(\%)$ & \\
\hline \multirow[t]{4}{*}{ Plaque index } & Excellent & $0(0)$ & $0(0)$ & $0(0)$ & $0(0)$ & $0(0)$ & 0.025 \\
\hline & Good & $0(0)$ & $4(5)$ & $0(0)$ & $3(6)$ & $7(3.46)$ & \\
\hline & Fair & $9(40.91)$ & 59 (73.75) & $20(40)$ & $26(52)$ & $114(56.44)$ & \\
\hline & Poor & $13(59.09)$ & $17(21.25)$ & $30(60)$ & $21(42)$ & $81(40.1)$ & 0.018 \\
\hline
\end{tabular}

Table 4: Assessment of caries index (decayed, missing, and filled teeth) (stratified by gender and DM/non-DM)

\begin{tabular}{lllll}
\hline & & $D M$ & \multicolumn{1}{c}{ Non-DM } & \\
\cline { 3 - 4 } Variables & $n(\%)$ & $n(\%)$ & p value \\
\hline Male & & & & \\
$\quad$ Caries index & $4-11$ & $1(4.55)$ & $24(30)$ & 0.162 \\
$\quad$ (DMFT) male & $11-18$ & $6(27.27)$ & $36(45)$ & \\
& $18-25$ & $7(31.82)$ & $15(18.75)$ & \\
& $25-32$ & $8(36.36)$ & $5(6.25)$ & \\
Female & & & & \\
Caries index & $8-14$ & $4(8)$ & $6(12)$ & \\
(DMFT) female & $14-20$ & $12(24)$ & $15(30)$ & \\
& $20-26$ & $19(38)$ & $16(32)$ & \\
& $26-32$ & $15(30)$ & $13(26)$ &
\end{tabular}

$13(26 \%)$ non-DM female patients, the range of caries index (DMFT) was 26 to 32 (Table 4).

\section{Discussion}

Diabetic mellitus is one of the major noncommunicable diseases in Saudi Arabia. Its prevalence was estimated to be around $32.8 \%$ during 2014. The trend is increasing with time especially in the urban regions compared to the rural regions. ${ }^{12}$ According to the data published by the World Health Organization (WHO) on DM, Saudi Arabia ranked as the second-largest country in the Middle East and seventh in the world per the diabetes rate. The complication of DM is massive in general as well as oral health leading to high mortality, morbidity, and vascular complications with low quality of life..$^{13}$

According to our best knowledge, in the past, few studies have been conducted in different regions of Saudi Arabia to determine the impact of DM on overall as well as oral health. However, we did not find any studies in Hail province, instead few measured oral health-related knowledge, attitude, and practice, but none specifically took data from DM patients in relation to oral health. ${ }^{14-16}$ A study from Riyadh reported that diabetic patients scored very low for health-related quality of life (HRQOL) questions compared with disease-free individuals. ${ }^{17}$ Another study by Al-Shehri et al. from Al-Khobar province documented that HRQOL among type 2 diabetes patients was lower compared to the control group and was influenced by many factors. ${ }^{18}$ Finding from another study conducted in Riyadh in 2012, on 283 T2DM patients concluded that gender, economic status, and complications of DM were independent risk factors for the majority of the subscales of HRQOL. ${ }^{19}$ The present study aims to measure the oral health status of DM patients in contrast with healthy individuals in Hail, Saudi Arabia. To our best knowledge, this is first study of its kind in Hail region.
Impact of DM on oral health is well-documented and very evident. According to the findings of a study from Medina by El-Khateeb, the DMFT index in a sample of young DM women living in Al Medina showed a high prevalence of dental caries compared to the non-DM women. ${ }^{8}$ The finding of the present study is somehow in line with the above-mentioned study. Results of the present study reported that the prevalence of plaque and dental caries was more common in diabetic patients when compared to the non-diabetic patients. Another study from Saudi Arabia studied the relationship between diabetes and periodontal diseases and reported plaque index and concluded that poor controlled diabetic patients showed an increased percentage of calculus and greater risks of periodontitis, which is in agreement with the finding of the present study. ${ }^{9}$

Our study reflected that the majority of the patients were aware of the oral health issues related to diabetes. However, most of the patients did not inform the dentist about their diabetes, as it is imperative for the patients to report their health status to the dentist to better understand their case. There are communication gaps between the healthcare provider and the patients. Thus, there is a need for awareness campaigns for patients, so that they get more information about the association/relation between oral health and diabetes.

The complications associated with oral health are more common in diabetic patients as compared to the nondiabetic patients. This is for both male and female patients visiting the College of Dentistry in the Hail region. Based on the findings of the current study, we suggested the need for awareness for the maintenance of good oral hygiene/oral health. A study conducted in Jordan reported that knowledge of DM and periodontal health must be given, alongside an eye should be kept on factors related to their knowledge and organize effective education programs. ${ }^{20}$ Similar results were expressed by Albert et al., ${ }^{19}$ which in turn are in contrast to the findings of our study. As documented by Lindenmeyer et al., at the time of diagnosis of diabetes, the patients should be provided with the written information concerning diabetes and its effects on oral health needs. ${ }^{2}$ Likewise, Valerio et al., ${ }^{21}$ has also reinforced to improve oral health, quality of life and literacy about oral health issues in diabetic adult population who are at risk of oral health problems.

\section{Conclusion}

The poor plaque index is statistically significant with both income and educational background. Thus, proper care and advice need to be given to the diabetic patients to avoid and lessen the occurrence of these oral health complications. The communication between the dentists and the patient needs to be improved, and a proper history and medical update of the patient need to be documented before the start of the treatment. If proper steps are taken to guide them properly, we can control the oral health complications such 
as caries and xerostomia. Dental awareness among the population of nonmajor cities can be beneficial in determining the education level of individuals to uplift the dental care and pinpoint the specific diseases, which in turn will be help for the future research as well as to build the necessary campaigns for educating the community.

\section{References}

1. Kudiyirickal MG, Pappachan JM. Diabetes mellitus and oral health. Endocrine 2015;49(1):27-34. DOI: 10.1007/s12020-014-0496-3.

2. Lindenmeyer A, Bowyer V, Roscoe J, et al. Oral health awareness and care preferences in patients with diabetes: a qualitative study. Fam Pract 2012;30(1):113-118. DOI: 10.1093/fampra/cms034.

3. Löe H.Periodontal disease: the sixth complication of diabetes mellitus. Diabetes Care 1993;16(1):329-334. DOI: 10.2337/diacare.16.1.329.

4. Mohamed HG, Idris SB, Ahmed MF, et al. Association between oral health status and type 2 diabetes mellitus among Sudanese adults: a matched case-control study. PLoS One 2013;8(12):e82158. DOI: 10.1371/journal.pone.0082158.

5. Silva MFA, Barbosa KGN, Pereira JV, et al. Prevalence of oral mucosal lesions among patients with diabetes mellitus types 1 and 2. An Bras Dermatol 2015;90(1):49-53. DOI: 10.1590/abd1806-4841.20153089.

6. Abdulaziz Al Dawish M, Alwin Robert A, Braham R, et al. Diabetes mellitus in Saudi Arabia: a review of the recent literature. Curr Diabetes Rev 2016;12(4):359-368. DOI: 10.2174/15733998116661507 24095130.

7. Al Hayek AA, Robert AA, Al Saeed A, et al. Factors associated with health-related quality of life among Saudi patients with type 2 diabetes mellitus: a cross-sectional survey. Diabetes Metab J 2014;38(3):220-229. DOI: 10.4093/dmj.2014.38.3.220.

8. El-Khateeb SM, Hamdan B, Gafar A, et al. Prevalence of dental caries among young women in central western region of Saudi Arabia. Int J Adv Dent Med Sci 2015;1(2):46-49.

9. Awartani FA. Evaluation of the relationship between type 2 diabetes and periodontal disease. Saudi Med J 2009;30(7):902-906.

10. Al-Rubeaan K, Al-Manaa H, Khoja T, et al. The Saudi abnormal glucose metabolism and diabetes impact study (SAUDI-DM). Ann Saudi Med 2014;34(6):465-475. DOI: 10.5144/0256-4947.2014.465.
11. Elasbali A, Ahmed $\mathrm{H}, \mathrm{Al}$-hazimi $\mathrm{A}$, et al. Current Burden of diabetes in Kingdom of Saudi Arabia in an epidemiological survey. Egypt Acad J Biolog Sci 2014;6(2):85-91.

12. Al-Rubeaan K, Al-Manaa HA, Khoja TA, et al. Epidemiology of abnormal glucose metabolism in a country facing its epidemic: SAUDI-DM study. J Diabetes 2015;7(5):622-632. DOI: 10.1111/17530407.12224.

13. Casanova L, Hughes F, Preshaw P. Diabetes and periodontal disease: a two-way relationship. Br Dent J 2014;217(8):433-437. DOI: 10.1038/ sj.bdj.2014.907.

14. Siddiqui AA, Shaikh S, Alam MK, et al. Assessment of attitude and practices towards oral health in a population of Saudi Arabian undergraduate students in the Ha'il region. Int Med J 2017;24(6): 478-481.

15. Siddiqui AA, Shaikh $S$, Aljanakh $M$, et al. Oral health related knowledge among the undergraduate students of Ha'il, Saudi Arabia, based on the recommendations of American Dental Association. Int Med J 2018;25(1):55-56.

16. Alshammary F, Aljohani F, Alkhuwayr F, et al. Measurement of parents' knowledge toward oral health of their children: an observational study from Hail, Saudi Arabia. J Contemp Dent Pract 2019;20(7):801-805.

17. AL-Aboudi IS, Hassali MA, Shafie AA, et al. A cross-sectional assessment of health-related quality of life among type 2 diabetes patients in Riyadh, Saudi Arabia. SAGE Open Med 2015;3:1-6. DOI: 10.1177/2050312115610129.

18. Al-Shehri AH, Taha AZ, Bahnassy AA, et al. Health-related quality of life in type 2 diabetic patients. Ann Saudi Med 2008;28(5):352-360. DOI: $10.5144 / 0256-4947.2008 .352$.

19. Albert DA, Ward A, Allweiss $P$, et al. Diabetes and oral disease: implications for health professionals. Ann N Y Acad Sci 2012;1255:1-15. DOI: 10.1111/j.1749-6632.2011.06460.x.

20. Al Habashneh R, Khader Y, Hammad MM, et al. Knowledge and awareness about diabetes and periodontal health among Jordanians. J Diabetes Complications 2010;24(6):409-414. DOI: 10.1016/ j.jdiacomp.2009.06.001.

21. Valerio $M A$, Kanjirath PP, Klausner $C P$, et al. A qualitative examination of patient awareness and understanding of type 2 diabetes and oral health care needs. Diabetes Res Clin Pract 2011;93(2):159-165. DOI: 10.1016/j.diabres.2011.03.034. 